Fecha de recepción: febrero 2019 Fecha de aceptación: marzo 2019 Versión final: mayo 2019

\section{Fragmentos de la Memoria. Memoria urbana de la Carrera Séptima entre 1950 y 1970 contada a través de fotografías de álbum de familia y narraciones de sus habitantes}

Johanna E. Zárate Hernández *

\begin{abstract}
Resumen: La memoria puede ser vista como una forma de hacer conciencia sobre sí mismo o como una forma de herencia que deja una generación a las que la suceden y es ésta investigación un recorrido visual por los conceptos de memoria, recuerdo y olvido. La memoria está constituida por una alta carga sensible, que se alimenta de los recuerdos individuales de los sujetos y que, al ser anexada a la colectividad, se hace visible, de manera que puede ser convertida en una forma de expresión de la memoria urbana de un grupo y, carga de esta manera, de significado los momentos de la experiencia del espacio existencial por el sujeto. La pregunta sobre la que se construye esta investigación se enfoca en la manera en que la memoria urbana de la Carrera Séptima de Bogotá entre 1950 y 1970 puede ser reconstruida mediante el análisis de fotografías extraídas de álbumes familiares y relatos de sus habitantes. Esta investigación adquiere potencia como documento en cuanto los sujetos que accedan a él, lo perciban como una concreción de la experiencia del espacio existencial del ciudadano de la época en cuestión, cargando las narraciones y las imágenes aquí recopiladas de simbolismo, en su propia experiencia vivida.
\end{abstract}

Palabras clave: Memoria - visibilidad - espacio

[Resúmenes en inglés y portugués en la página 252]

${ }^{(*)}$ Profesional en Diseño Gráfico de la Universidad Jorge Tadeo Lozano y Especialista en Edición Digital y Multimedia de la misma institución, Maestra en Estética e Historia del Arte. Hace parte del grupo Diseño, pensamiento y creación del programa de Diseño Industrial, en la Facultad de Artes y Diseño, de la Universidad Jorge Tadeo Lozano, docente de Teoría del diseño industrial, Taller de diseño industrial (Interacciones) y proyecto de grado.

\title{
Introducción
}

Esta investigación es un recorrido visual por los conceptos de memoria, recuerdo y olvido, planteados por Aristóteles, Joël Candau y Paul Ricouer, las ideas de memoria urbana de Armando Silva y Jafrrey K. Olik, las relaciones de fotografía y memoria de Boris Kossoy, Susan Sontang, Jean Marie Shaeffer, Peter Burke, Lorenzo Vilches, Eduardo Serrano y 
Edward Goyeneche. La noción de espacio y ciudad relacionadas con las ideas de territorio plateado por Silva, Massimo Cacciari, José Luis Romero, Cristian Norberg Shultz y las aproximaciones al contexto histórico de Pablo Páramo, Mónica Cuervo y Ana María Carreira. Son todos estos elementos constitutivos de la memoria del habitante de la ciudad, que se convierte en una memoria urbana, en este caso de la Carrera Séptima de Bogotá en un marco temporal definido.

La memoria puede ser vista como una forma de hacer conciencia sobre sí mismo o como una forma de herencia que deja una generación a las que la suceden. Pero en todo caso, la memoria está constituida por una alta carga sensible, que se alimenta de los recuerdos individuales de los sujetos y que, al ser anexada a la colectividad, se hace visible, de manera que puede ser convertida en una forma de expresión de la memoria urbana de un grupo y, carga de esta manera, de significado los momentos de la experiencia del espacio existencial por el sujeto. Esta memoria, que intenta rescatar la experiencia vivida, existe en cuanto alguien se toma el tiempo y el trabajo de organizar y archivar las narraciones y sus vestigios materiales, para mantenerla; así, se crea un refugio que permite conservarla viva como una realidad latente.

Esto evidencia cómo los recuerdos aislados podrían ser inútiles en estos términos, al permanecer en la intimidad, pero se convierten es un precioso capital al unirse a la memoria urbana. La pregunta sobre la que se construye esta investigación se enfoca en la manera en que la memoria urbana de la Carrera Séptima de Bogotá entre 1950 y 1970, puede ser reconstruida mediante el análisis de fotografías extraídas de álbumes familiares y relatos de sus habitantes.

Esta investigación toma forma, en tanto busca hacer relevante reconstruir la experiencia del espacio existencial de los ciudadanos comunes de una ciudad, representada en un lugar simbólico y trascendente de Bogotá, como es la Carrera Séptima en una época de rupturas y cambios tanto para la capital como para el país: las dos décadas subsiguientes al Bogotazo. Así, los eventos comunes y cotidianos son, en la actualidad, merecedores de ser recordados y convertidos en parte constitutiva de una memoria que puede ofrecer una visión de la existencia del sujeto común, mediante la narración de su experiencia del espacio existencial, anclada a un archivo personal manifiesto en su álbum de familia y sistematizado por esta investigación. Es, entonces, en este momento, que la fotografía que detona el recuerdo, actúa como testimonio del mismo y cambia su sentido testimonial íntimo para convertirse en archivo de memoria urbana al ser analizado y organizado con fines analíticos e interpretativos. Este proceso permite, de alguna manera, estructurar las memorias particulares.

El producto de esta investigación adquiere potencia como documento trascendente en cuanto los sujetos que accedan a él, lo perciban como una concreción de la experiencia del espacio existencial del ciudadano bogotano de la época en cuestión, cargando las narraciones y las imágenes aquí recopiladas de simbolismo, en su propia experiencia vivida. Es entonces, el documento presentado a continuación, parte del resultado de un proceso de recopilación de narraciones y fotografías, que son sometidas a una etapa descriptiva, reflexiva y, finalmente, una interpretativa, que presenta unas conclusiones que pretenden arrojar unas pequeñas luces de lo que podría ser una reconstrucción de un fragmento de la memoria urbana del ciudadano común de Bogotá en el siglo XX. 


\section{Memoria Urbana}

Es necesario entrar a detallar las particularidades de lo que se conoce como memoria urbana, que si bien, actúa sobre las premisas generales de la memoria, posee unas características específicas que la envuelven y limitan. Se entiende entonces que la memoria no es unificada, ni uniforme en un colectivo social, la memoria, gracias a su carácter individualizante de los acontecimientos colectivos, permite que cada sujeto sea el historiador de sí mismo, son entonces las formas de memoria que el colectivo implementa en estos casos, que se relacionan con la conmemoración de acontecimientos significativos, la patrimonialización de huellas de la experiencia colectiva y la producción de memoria que busca afianzar el concepto de ciudadanía, para desarrollar una identidad sobre la pluralidad étnica, cultural, religiosa y/o política que permita construir el sentido contemporáneo de nación.

Se podría entonces afirmar que, la diferencia entre el concepto de memoria y memoria urbana, yace no en el cómo, sino en el qué se recuerda y puede plantearse a la memoria urbana como un hecho social, ésta característica le permite a los individuos y a los grupos constituir una identidad. Ésta necesidad de construir una identidad mediante una memoria urbana tiene que ver con el cambio que produce el habitar la ciudad para el hombre moderno, ahora ciudadano, y que parece carecer de un pasado continuo, pero estar sujeto a la continuidad de la reproducción social.

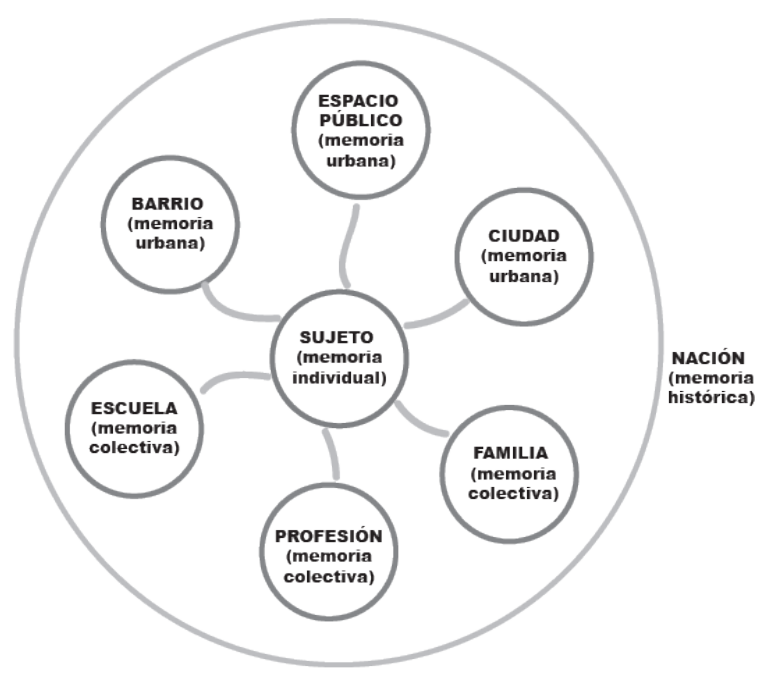

Figura 1. Esquema niveles de memoria. Elaboración propia. 2017

Es la memoria del ciudadano moderno, al parecer, una forma discursiva que representa lo que ya no se puede experimentar de forma espontánea. La memoria urbana es una construcción colectiva de recuerdos en torno a "cosas" individuales, que se convierten en genéricas y 
similares para una colectividad, y que son transmitidas a las siguientes generaciones como memoria. Tomando esto de base, se puede entender el por qué esta investigación habla de reconstruir memoria urbana mediante el uso de fotografías y narraciones de los habitantes, ya que, mediante el análisis y la comparación de estas fuentes primarias, se pueden establecer entonces las similitudes entre esas individualidades que, permitan encontrar generalidades que hayan sido o puedan ser transmitidas a las generaciones actuales y futuras de la ciudad de Bogotá y que aporten a la construcción de una memoria urbana más detallada y específica con respecto a la experiencia de habitar la Carrera Séptima de Bogotá entre 1950 y 1970 como las décadas iniciales y decisivas para la construcción de la Bogotá que se conoce el día de hoy, una ciudad multi étnica, pluricultural y con una amplia gama religiosa, política y económica en la cual las generalizaciones se han hecho casi imposibles.

\section{Las fotografías}

Las narraciones que soportaban el paso de los recuerdos sobre acontecimientos memorables de generación en generación mediante la transmisión oral, requieren en la modernidad un soporte externo, un detonante que permita realizar la transmisión de la memoria. Estos detonantes son, en esta investigación, las fotografías que se convierten aparentemente en una forma moderna de archivar externamente la memoria y poseer el territorio. Las fotografías almacenadas en el álbum de fotografías son los detonantes de las narraciones sobre acontecimientos pasados trascendentes para la construcción de la memoria individual. El problema se constituye en la validación de memoria urbana que puedan tener estos relatos y fotografías como una construcción social no oficial cuyo lugar de divulgación es la sala de estar de los hogares Bogotanos.

La fotografía, es entendida como una estrategia de representación "material" de la experiencia vivida por el sujeto, que las almacena en su álbum familiar sin ninguna pretensión histórica o documental, más allá de la memoria privada y autobiográfica. Esa memoria autobiográfica sucede en un territorio conquistado y mantenido por el sujeto que lo habita como espacio existencial. "Aun más: una conquista territorial solo se convierte en real después del, o más exactamente: por el ritual de toma de posesión, el cual no es sino una copia del acto primordial de la creación del mundo" (Eliade, 1951, pág. 19) En otras palabras para que un sujeto considere un espacio como su territorio o espacio existencial debe transformarlo y poseerlo, conferirle formas propias que lo conviertan en algo real y, puede ser el acto de tomarse una fotografía en él, una forma moderna de creación y posesión de dicho territorio. Es la fotografía una captadora de los diferentes contextos socio gráficos que apoya la preservación de la memoria visual en: fragmentos de mundo, escenarios, personajes, eventos continuos contrastes y transformaciones. "La fotografía es un intrigante documento visual, cuyo contenido es al mismo tiempo revelador de informaciones y detonador de emociones" (Kossoy, 2001, pág. 23) y por que no, de recuerdos.

Cabe aclarar que la fotografía que analiza esta investigación estaba archivada en el álbum de familia y sirve en este caso para comprender las prácticas sociales públicas transmitidas a través del relato familiar, para conservar la memoria de la vida experimentada ya sea por 
los mismos sujetos o por sus ancestros. Por otro lado, es importante dejar en claro que esta investigación no indagó sobre los orígenes de la fotografía o sobre sus creadores.

Boris Kossoy plantea dos tipos de realidades, la primera afirma que es posible recuperar la vida pasada y es la fotografía una "prueba" de su existencia, lo cual hace a la imagen fotográfica una "nueva realidad". La segunda realidad planteada, es la del documento, en esta realidad, la fotografía del pasado forma parte del mundo y su vida, es la vida del documento. La fotografía se caracteriza entonces por estar constituida por una condición dual formada por la relación indivisible entre materia y expresión, posee informaciones implícitas y explícitas que dependen de la génesis e historia como documento y de su entendimiento como fragmento de la realidad pasada, registrada mediante procedimientos técnicos y seleccionada para el estudio.

Es muy probable que la imagen que todos tenemos de nuestro pasado familiar provenga de una foto. La familia encontró en los mismos inicios de la fotografía su medio más amplio de constatación... De otro lado, en el siglo pasado ocurrió una exaltación del sentimiento familiar de una manera hasta entonces desconocida, convertido en orgullo y fundamento de la sociedad... Las fotos familiares, conservadas en algún sobre o, más cuidadosamente, ordenadas en un álbum son un tesoro de memoria. (Rodríguez, 1996, pág. 12)

La fotografía ejerce un papel de autoridad en las sociedades modernas, en un momento de la historia de la humanidad en que como nunca antes, la imagen construye la "realidad" del hombre. Es en este periodo histórico en el cual la fotografía parece adquirir gran importancia, se entiende a la fotografía como una forma de adquirir y sus formas adquisitivas tienen tres manifestaciones: primera, la fotografía permite la posesión subrogada de una cosa o una persona. Esta adquisición simple convierte a la fotografía en objeto único. Segunda, la fotografía como elemento de consumo de acontecimientos de la experiencia personal y la del otro, que se ve afectada por los hábitos del consumismo. Tercera, la adquisición mediante máquinas reproductoras o duplicadoras de imágenes que están dotadas de información más que de experiencia.

Las fotografías son en efecto experiencia capturada y la cámara es el arma ideal de la conciencia es su talante codicioso... Fotografíar es apropiarse de lo fotografiado. Significa establecer con el mundo una relación determinada que parece conocimiento, y por lo tanto, poder (Sontag, 1973, pág. 14 ).

La memoria se apoya en "imágenes mentales" que se detonan en este caso con la visualización de imágenes fotográficas, las imágenes no son tomadas entonces en esta investigación como verificadoras del relato oral, sino que por el contrario son los detonadores o razón de ser del relato. Algunas imágenes pueden ser vistas como "agentes históricos" como lo plantea Peter Burke, ya que guardan memoria de los acontecimientos y además pueden influir en la forma en que los acontecimientos son vistos en su época y por que no, en épocas posteriores. 
La imagen fotográfica, al igual que el cine, le permite al espectador tener la sensación de ser testigo de primera mano de los acontecimientos, aunque en realidad dicha sensación es una ilusión, ya que la fotografía solo permite observar una fracción posiblemente sesgada de los acontecimientos. Sesgada en cuanto ha pasado por el proceso fotográfico, la toma, la pose o las intenciones del fotógrafo o de quien hizo el encargo.

La fotografía captura el tiempo descomponiéndolo en momentos, y la visualización de la imagen fotográfica evidencia la distancia temporal con un acontecimiento pasado. La fotografía es la imagen inmóvil del tiempo que puede remitir a una entidad o a un acontecimiento y su naturaleza es enmarcada por la distinción de los actos del lenguaje utilizados para describir el "contenido" de la imagen. El sujeto utiliza para dicha descripción los universos de referencias correspondientes a lo descrito, la fotografía se convierte en la "prueba" de existencia de una entidad o de un acontecimiento por medio de una relación perceptual. La fotografía recuerdo o rememoración, requiere de un proceso de reconocimiento entre la "imagen artificio" y la "visión originaria" esto se realiza mediante los saberes laterales que permiten la recepción de la imagen fotográfica, la relación con la información adicional al que proporciona la imagen y la inserción en la memoria perceptual gracias a la experiencia. "La fotografía (...) revoluciona la memoria: la multiplica y la democratiza, le da una precisión y una verdad visual nunca antes alcanzadas, permitiendo así guardar la memoria del tiempo y de la evolución cronológica" (Le Goff Jacques, en Kossoy, 2001, pág. 116).

$\mathrm{Al}$ realizar un análisis del sentido social y memorial de las fotografías, se plantea que el contenido es indispensable en el uso social de la imagen al tener en cuenta la demanda social de la fotografía, la relación que tiene con la memoria y la necesidad individual de la memoria de acontecimientos cotidianos que a la luz de la colectividad pueden no ser trascendentales para la colectividad, por que no transformaron la historia, pero que a nivel personal evidencian acontecimientos trascendentales y merecedores de ser atesorados en el álbum familiar para ser sujetos de la narración y la rememoración que los mantiene vivos en la memoria de una pequeña colectividad, y que ahora, son extraídos de su espacio privado, para ser expuestos en el ámbito público como vestigio de una memoria colectiva que parece engranarse como una totalidad que conforma una memoria urbana en un territorio y que contiene recuerdos sobre acontecimientos que aunque se dan en espacio público, son parte de la narración de memoria del espacio existencial privado y familiar de los sujetos. Por lo tanto, estas fotografías analizadas en la investigación provenientes de los álbumes de familia, son para sus dueños tesoros de memoria y a su vez, objetos que sacralizaron un acontecimiento, un lugar, un tiempo o sujetos, que a su juicio deben ser inmortalizados.

\section{Interpretación}

El análisis interpretativo del corpus de la investigación busca encontrar un puente entre la narración, la imagen fotográfica y la memoria, que permita proponer una reconstrucción de la memoria urbana de la Carrera Séptima de Bogotá en las décadas de los 50 a los 70. Para ello se plantea una relación de la fotografía, la memoria urbana y la experiencia del espacio existencial o territorio. Este análisis de tipo teórico tiene una representación material plasmada en cartografías simbólicas que sirven para caracterizar la memoria urbana de los ciudadanos 
bogotanos desde los acontecimientos cotidianos ocurridos en la Carrera Séptima de Bogotá desde 1948 hasta la década de los 70, que marca el cambio político y económico del país, y que incide directamente en la ciudad como lugar de experiencia para los ciudadanos.

Al ver las fotos y preguntar al entrevistado qué recuerda sobre el acontecimiento capturado por la foto, la fecha, los protagonistas y el lugar, se evidencia cómo la Carrera Séptima es un espacio sobre el cual se detonan fácilmente los recuerdos, pero las calles específicas se deducen en la mayoría de los casos, mediante la observación del material fotográfico. El tipo de relato varía según el detonante de la reminiscencia (fotografía y/o relato), ya que en algunos casos se inicia por la narración y, en medio de la entrevista, la persona recuerda tener fotos de la época y lugar; luego procede a localizarlas, lo que ayuda a precisar detalles sobre el recuerdo. En otros casos, la búsqueda de la foto es el inicio y el ver la foto detona el recuerdo y, por lo tanto, es el punto inicial del relato.

Este proceso que evoca la memoria mediante la fotografía y la narración oral, evidencia que la inexactitud de las fechas puede relacionarse con la percepción del tiempo que tiene el ciudadano en el espacio existencial o territorio. Esto es, la descripción del espacio y el tiempo adquieren mayor exactitud y detalle, según la actividad que se esté recordando. En este sentido, el tiempo es para el relator, una percepción subjetiva; por lo tanto, se da en relación con una corporalidad que encarna una existencia presente o pasada en cuanto la revive en su mente y la ve en parte reflejada en la fotografía.

Con respecto a la evidencia que retiene la fotografía sobre un pasado en el cual se relaciona la tríada tiempo-espacio-cuerpo, es importante destacar la relación entre el sujeto fotografiado y el fotógrafo, es decir, aunque no nos detenemos a indagar sobre la intención del creador, sí se puede analizar, cómo es evidente la existencia tácita del otro detrás de la lente de la cámara, y es éste sujeto latente el que cede el puesto al observador de la foto. Ahora, para complejizar más el asunto, aquel sujeto que aparece en la fotografía experienciando el mundo, es también ahora, en el presente, el observador de sí mismo en el pasado. Ahora, regresando al espacio existencial y a la dimensión de la experiencia del espacio de expresión, se ve en las fotos cómo la familiaridad con la toma y la espontaneidad de la acción es subjetiva. Cada sujeto se relaciona no tan solo con el espacio, el tiempo y el cuerpo de forma particular, sino que también existen dichas particularidades con respecto a la relación con la fotografía misma. En algunas fotografías se ven sujetos solos, en otras aparecen parejas o grupos. Algunas fotos son planeadas y ejecutadas con precaución, y en otros casos son claramente espontáneas.

Las imágenes mentales que sustentan el recuerdo y la memoria, se apoyan en la mayoría de los casos de esta investigación, en la fotografía del álbum de familia, aunque la fotografía no muestra todo lo que la narración describe costumbres, valores, recuerdos, acontecimientos concretos la mayoría de las fotos, muestran personas en estado suspendido, ya sea caminando o posando en determinados espacios físicos de la Carrera Séptima o sus alrededores. Por tanto, la fotografía actúa solo como detonante del recuerdo, pero la rememoración reconstruye el resto del recuerdo en el relato resultante.

En la etapa de revisión y análisis se revisan de forma separada las imágenes y los relatos o narraciones. La muestra total seleccionada para el análisis final cuenta con treinta y seis (36) fotografías, de las cuales (34) cumplen con la especificación del marco de tiempo; las otras dos exceden por un breve margen de 5 años la fecha y, aunque se analizan por su pertinencia con 
respecto a los relatos, no hacen parte de las conclusiones generales por su variable temporal. Para realizar el análisis de expresión corporal se tomó como base el modelo conceptual desarrollado por Edward Hall, en su texto La dimensión oculta, en el cual el autor explica los resultados de su investigación sobre el uso que el hombre hace del espacio y cómo esta relación es también una forma de comunicación humana, es así, que el autor plantea que por el espacio social personal y por la forma en que el hombre lo percibe.

De esta manera, al realizar el análisis de las fotografías -como detonantes de memoria-, desde la proxemística se busca indagar en ellas datos que revelen la experiencia del espacio existencial con respecto al territorio y a la ciudad. Si los indicadores del espacio con espacio existencial y territorio, se puede decir que estos dos indicadores se relacionan con lo que explica Edward Hall en su modelo organizativo y que aquí se denominará tipología del espacio, como espacio fijo, espacio semifijo y espacio informal.

El primero es el espacio fijo y rígido, en el cual las actividades son específicas y constantes. En este espacio el hombre ha creado estructuras inamovibles, no solo desde el aspecto físico, sino desde las manifestaciones que modelan el comportamiento del sujeto. El siguiente espacio de características semifijas es aquel que relaciona el sujeto con los objetos "en" el espacio como el mobiliario y los objetos en este espacio. Desde allí se puede analizar la relación entre el cuerpo y los objetos que lo rodean y median sus acciones "en" un lugar. Hay que tener en cuenta, por otra parte, que lo que en una cultura constituye espacio de características fijas, en otra puede serlo de caracteres semifijos, y viceversa (Hall, 1973, pág. 174). Estos dos espacios son los que establecen el espacio existencial y el territorio.

También existe el espacio informal, que comprende la distancia que se mantiene en sus encuentros con los demás (Hall, 1973, pág. 179). En este nivel se habla de cuatro distancias, a saber: la distancia íntima, que es la de contacto físico y proximidad, en la cual tienen lugar los actos amorosos, la lucha, el consuelo o el afecto. Luego está la distancia personal, que es una distancia que permite el contacto físico con el otro para sujetar y asir, de modo que evidencia las relaciones cercanas con amigos, familia y pareja. Continuando se encuentra la distancia social, es aquella que marca el límite de la dominación, como lo denomina Edward Hall; es decir, es una distancia que no propicia el contacto físico, es la necesaria para el trabajo, el convivir en la oficina o para la conversación. Por último, está la distancia pública, que es aquella que se usa para dirigirse a un grupo de personas, ideal para las figuras públicas. Con respecto a las distancias, estas se relacionaron con la variable del ciudadano, en lo que tiene que ver con los indicadores de prácticas, espacios y tiempos, ya sean de tipo individual o colectivo. Y, si el análisis de esta investigación se hace desde la experiencia en espacio existencial, la subjetividad en su facticidad y corporalidad es de gran pertinencia. Edward Hall señala que existen unas diferencias que determinan las distancias en los territorios en los cuales se desenvuelve el sujeto según las variables culturales. Estas variaciones subyacen en una experiencia del espacio existencial diferente en cada cultura, condicionada por el tiempo - espacio - cuerpo en el cual habita el sujeto, lo cual modifica el mundo sensorial que experiencia un sujeto de acuerdo a su cultura. Aun así, como se plantea aquí, esta aproximación, es tan solo una base sobre la cual se construye un cuadro que permite un análisis inicial y general que se profundiza y especializa al ser cruzada con el análisis interpretativo que permiten las narraciones. La idea de esta categoría de distancia es, en 
principio, revisar la coincidencia de la Tabla 1, desarrollada para esta investigación con base en la propuesta teórica de Hall, la fotografía y posteriormente el relato.

Dentro de este análisis también se consideran las variables del territorio, en el cual aparece el territorio público, espacio de libre acceso que no es controlado por una sola persona de forma permanente; después está el territorio de interacción, que es el espacio de congregación o reunión informal; le sigue el territorio habitual, que es el espacio individual y controlado, y para finalizar, aparece el territorio corporal, aquel que rodea nuestro cuerpo, lo que podríamos llamar espacio personal. Esta división en territorios sirve para analizar las prácticas del sujeto en el espacio público.

La Tabla 1, que se muestra a continuación, se utiliza para el análisis individual de cada fotografía, aquí se mostrará su aplicación en una imagen a manera de ejemplo.

\begin{tabular}{|c|c|c|}
\hline TERRITORIO & TIPOLOGÍA & DISTANCIAS \\
\hline ESPACIO PÚBLICO (1) & FIJO (5) & \\
\hline ESPACIO DE INTERACCIÓN (2) & SEMIFIJO (6) & \\
\hline ESPACIO HABITUAL (3) & \multirow{4}{*}{ INFORMAL (7) } & ÍNTIMA (A) \\
\hline \multirow[t]{3}{*}{ ESPACIO CORPORAL (4) } & & PERSONAL (B) \\
\hline & & SOCIAL ( C) \\
\hline & & PÚBLICA (D) \\
\hline
\end{tabular}

Tabla 1. Categorías de análisis aplicadas a las fotografías. Fuente: Elaboración propia. 2014.

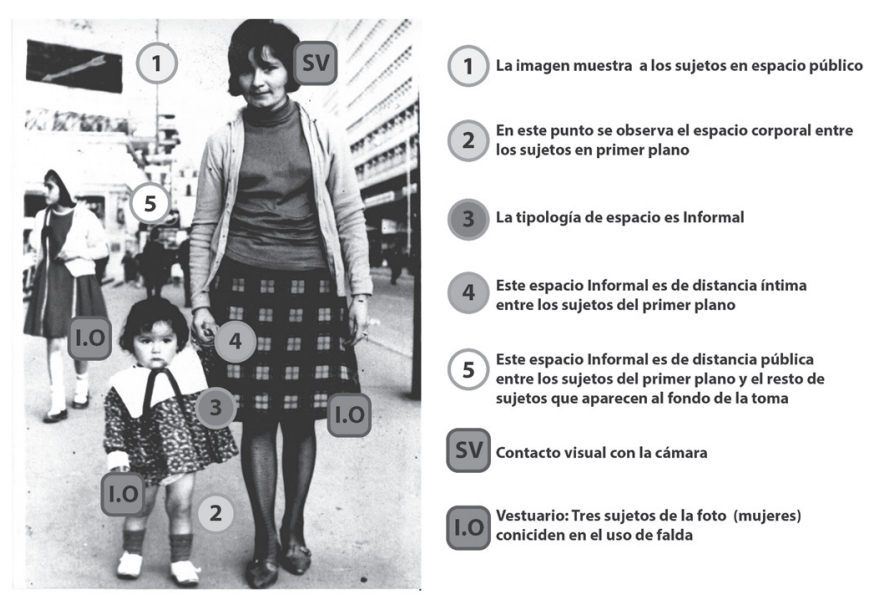

Figura 2. Ejemplo de aplicación de la Tabla 1. 
A todo lo que se ha detallado anteriormente se hace necesario agregar un par de variables adicionales para completar el modelo de análisis. La primera de estas variables está contenida en lo que Edward Hall denomina territorialidad del sujeto. Utilizando como punto de inicio esta teoría, se tendrá en cuenta lo que se llamará desde ahora signo visual (SV). El signo visual se utiliza para analizar la actitud visual de los sujetos del primer plano de la foto. Aquí es preciso determinar actitudes como si quienes aparecen en la fotografía observan o no al fotógrafo, el fotógrafo es, a su vez, el observador y, aunque no nos ocupamos de él ni de su intención, sí es importante la mirada del sujeto, pues ayuda a entender la relación con el otro tras la lente, y este otro, cuya existencia es tácita en la toma, como sujeto latente, es la posición que adopta en la actualidad el observador de la fotografía. En este sentido, el signo visual (SV) es el que permite determinar la experiencia proxemística del sujeto con respecto a la distancia que tiene el sujeto fotografiado, con el observador. Este dato aporta información a la investigación sobre las relaciones de los sujetos en el espacio existencial urbano, en este caso, la relación con este sujeto latente.

La segunda de estas variables es lo que se denominará inventario objetual (IO). Será una serie de objetos que pertenecen al espacio semifijo del sujeto y que permiten analizar las consistencias de estas relaciones en las muestras de análisis, las actividades, los lugares y los sujetos. Este inventario objetual comprende el vestuario, accesorios y objetos que se puedan considerar elementos de participación activa en la constitución de la memoria urbana en el espacio existencial.

Con respecto al nivel narrativo de la memoria, lo que se ha denominado la expresión narrativa, el análisis se enfoca en variables del discurso. Por ejemplo, los términos referidos al espacio: en, sobre, junto, bajo, lejos, cerca, unido, encerrado, afuera, adentro, entre otros. La siguiente variable es la sensorial. En esta se resaltan las descripciones como: visto, sentido, percibido, pequeño, grande, alto, gris, elegante, deforme, silenciado, distorsionado, suave, duro, liso, salado, ahumado, dulce, desagradable, molesto, miserable, entre otras. Por último, se tendrán en cuenta las variables descriptivas o históricas en las cuales los entrevistados enuncian datos sobre acontecimientos, hechos, lugares o personajes que se puedan relacionar con la historia de la ciudad. Para facilitar el análisis, se realizó un cuadro de análisis (Tabla 2). Aquí se muestra un ejemplo de su aplicación.

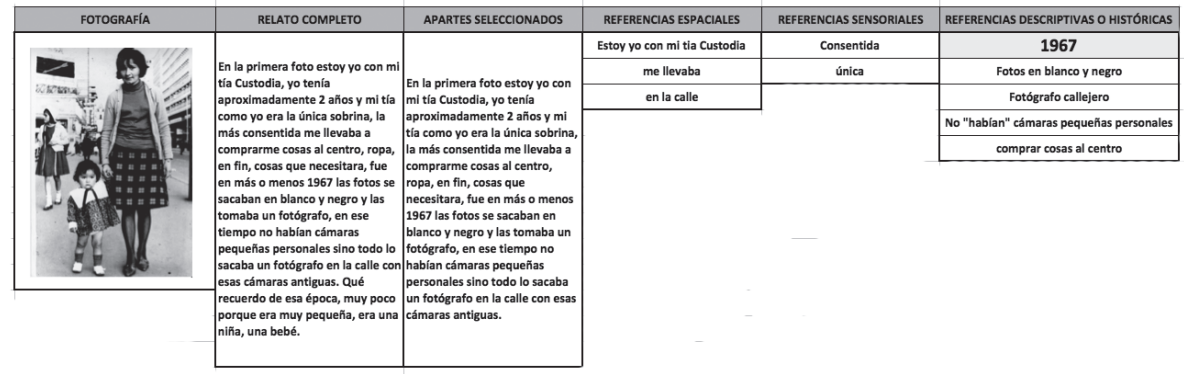

Tabla 2: Categorías de análisis aplicadas a las narraciones. Fuente: Elaboración propia. 2014. 


\section{Hallazgos sobre las Fotografías}

En primer lugar se observa que el sujeto puede ser un peatón ocasional o un trabajador de oficina que va por la calle. Sin embargo, en estos casos nos encontramos con que al fondo de la toma hay otros ciudadanos transitando por la calle, la plaza o el parque. Así, aunque el sujeto asuma que su experiencia es individual, está siendo afectada de forma directa por los otros sujetos que están con él, habitando su territorio, en el espacio público, en el espacio existencial. Además, comparten la misma tipología de espacio, en este caso, en su mayoría, un espacio informal, en el cual la distancia ayuda a determinar la posible relación o cercanía con los otros sujetos de la toma. Es así, entonces, que sin importar si los sujetos que aparecen en la toma se conozcan o no, están teniendo una experiencia colectiva del espacio existencial, y se están vinculando mutuamente a la memoria colectiva urbana del lugar.

Por otro lado, se observan las fotos que son intencionalmente colectivas, es decir, aquellas en las cuales en el primer plano aparece más de un sujeto. Aquí no existe tan solo de forma obvia, una experiencia colectiva para el sujeto, sino que su habitar en la ciudad está relacionado con unas prácticas y acontecimientos que permiten estar en el mundo mediante una corporalidad, que además se evidencia en la distancia que tienen unos de otros en la fotografía. En este caso, se observa en las fotos de familia, una distancia íntima, como lo plantea la proxemística. Así, ese espacio informal, dentro de un territorio público y corporal, admite también experiencias íntimas y cercanas; es así que la ciudad, constituida por la calle, la plaza o el parque, al ser un espacio de libre acceso, y que no es controlado por un solo sujeto, es propicio para la reunión o el tránsito de sujetos que en este espacio - tiempo manifiestan su relación mediante la distancia de sus cuerpos.

Otro hallazgo es la conformación el territorio clasificado como espacio público. Este espacio público, co-existe en el espacio corporal que aparece en la toma. Estos dos territorios evidencian las tipologías de espacios. Aquí la mayoría de las imágenes evidencian un espacio informal, ya que lo que capturan es la existencia de los sujetos en el espacio. La ciudad no es la protagonista de las tomas y los acontecimientos reflejados son, en general, de circulación. Esto es, en su mayoría, por que las tomas muestran a ciudadanos en su práctica como peatón, independientemente de su relación con el espacio no importa si son trabajadores de oficina, estudiantes, conductores o peatones ocasionales; los sujetos aparecen caminando en la calle, posando en la plaza pública o en el parque. Las fotografías no reflejan prácticas como juego o trabajo. En realidad, muestran la acción de trasladarse de un punto $\mathrm{A}$ a un punto $\mathrm{B}$, con alguna finalidad que no es clara en la foto. Esto evidencia cómo la calle analizada es una zona en la cual el sujeto habita por múltiples razones: por costumbre, por obligación, por necesidad o por gusto.

Si bien, como se dijo anteriormente, la mayoría de las fotos muestra personas congeladas en la acción de desplazamiento, hay también imágenes en las cuales la intención de pose es clara. En este caso estos límites con una distancia tan corta y una actitud más dispuesta a la toma, demuestran la relación existente con la práctica de la fotografía como acción y acontecimiento que permite que el sujeto experiencie el espacio existencial. Así, vemos que algunas de las fotografías muestran poses más rígidas, lo que sugiere una relación distante con el fotógrafo y la acción en sí. 